\title{
MECHANICAL FATIGUE TEST OF ALUMINIUM COMPOSITE PANEL (ACP) WITH ARAMID NIDA-CORE UNDER CYCLIC BENDING
}

\author{
AIT SAID Ahcene', BEY Kamel ${ }^{1}$, MZAD Hocine ${ }^{2 *}$ \\ ${ }^{1}$ Badji Mokhtar University of Annaba, Laboratory of Industrial Mechanics, Faculty of Engineering \\ Sciences, P.O. Box 12, DZ-23000, Algeria \\ ${ }^{2 *}$ Badji Mokhtar University of Annaba, Department of Mechanical Engineering, Faculty of Engineering \\ Sciences, P.O. Box 12, DZ-23000, Algeria, e-mail: h_mzad@yahoo.fr
}

\begin{abstract}
The selection of a composite material for any application will involve selection of reinforcing fibre and matrix, and their fractional volume in the resulting material. A properly selected combination will give a composite material high strength and stiffness, low weight, excellent fatigue and corrosion resistance. The present experimental work is a contribution to the study of the mechanical fatigue behaviour under 3-point bending stress, of aramid/aluminium composite panel with honeycomb core. The tests were performed on four specimens for three cyclic loadings $(90 \%, 80 \%$ and $70 \%)$, and imposed deformation with a load ratio of 0.2 and a frequency of $5 \mathrm{~Hz}$. The results show that the optimal load ensuring better service resistance of the experimented sandwich panel is 0.7 of the material elastic limit $(720 \mathrm{~N})$. Observation using optical microscope of fracture faces in static and cyclic flexion showed the different damage modes of skins and core.
\end{abstract}

KEYWORDS: Sandwich material, Aramid/aluminium, Nida-core, Tests, Bending, Fatigue, Fractography

\section{Introduction}

Nowadays, due to their resistance and low density sandwich composites are well-known especially in aircrafts and shipbuilding. They arouse great interest among researchers and a number of works are devoted to them. Due to the wide range of properties such as high strength, stiffness, high damping capacity, vibration resistance and the lightweight, metal/polymer/metal sandwich composites find their application as various body-parts in the automotive industry. Many structural parameters affect the mechanical behaviour of these complex systems: The nature of material constituents, the stacking sequences, the relative thicknesses of the different layers as well as the experimental techniques used [1,2]. Usually, the performance of a composite material is tested by experiments like the experimental work carried out on the fatigue, impact and creep behaviour of cement matrix composites with improved ageing characteristics [3].

The fatigue characteristics of shear loaded honeycomb sandwich beams are experimentally investigated through constant load amplitude tests [4]. Honeycomb sandwich configurations are test differentiated only by the orientation of the honeycomb core. The fatigue test results are presented in standard $\mathrm{S}-\mathrm{N}$ diagrams with a best curve fit to the experimental data. Observations of the fracture surfaces revealed the different modes of damages causing the material fracture. The lifetimes are characterized by the Wöhler curves which evidenced the influence of the reinforcement orientation on the material endurance [5].

The fatigue crack growth behaviour of pre-cracked aluminium substrates with bonded composite patches was investigated experimentally and analytically [6]. Tension-tension fatigue tests were conducted on the substrates to establish their fatigue behaviour for 
comparing with the repaired specimens. Recent efforts into the research and development of reinforced bonded joints for composite laminates are discussed [7]. An experimental study investigates the behaviour of co-bonded carbon fibre reinforced plastics joints with a novel design incorporating a through the thickness local reinforcement.

The fatigue reliability of Gr/PEEK composites has been investigated experimentally [8]. The accumulation of fatigue damage was determined, using the residual strength degradation model represented by a two-parameter Weibull distribution function.

Extensive experimental and numerical investigations were carried out for the characterization of metal plastic sandwiches, which are composed of two thin metallic surface layers and a polymer core [9]. Compared to conventional sheet metal materials the structural modification caused by sandwich design provides an increased specific flexural rigidity.

Many papers were devoted to the fatigue behaviour of reinforced composite materials [1012], under different loading conditions, with different types of glass fibre and surface modified alumina reinforced AZ91E magnesium based composites. A modelling of a stressstrain state of a detachable threaded joint with a rope thread was conducted. Impact improvement and fatigue strength due to interactions between the matrix and reinforcement were also discussed.

The dynamic mechanical properties and the morphology of ternary nanocomposites were scrupulously investigated [13]. A dynamic mechanical analysis was used to characterize the storage modulus and loss factor.

$\mathrm{Xu}$ et al. investigate [14] the effects of complex state of stress on the compressive behaviour of 3D carbon/carbon composites by application of uniaxial and biaxial loadings using a specially developed Zwick cruciform testing facility. A semi-analytical method is proposed to determine the stress components in the gauge section of the biaxial specimen.

The specific damping capacity for composite sandwich panels made of fibre-reinforced plastic has been calculated [15]. A highly damped honeycomb material such as the polymerbased Nomex has been considered as the sandwich core.

Aiming to reduce synthetic fibre applications, a research of hybridization of natural fibre reinforcement was conducted to determine the effect of layering sequence on the mechanical performance of hybrid woven jute-roselle [16]. The results showed that the hybridization of jute-roselle provided was significant, especially on the flexural and impact performance.

A newly performed finite element modelling focuses on the importance of cohesive zone model versus the previously conducted numerical simulation and experimental results for buckling of sandwich composite structures [17]. The study enables to account for delamination growth between shells and core and improve the correlation results with those of experiments.

This study is dedicated to a systematic experimental investigation of the mechanical fatigue behaviour of a sandwich-structured composite. In the framework of experiments, panels were exposed to two types of stressing: static as well as impact stressing. The specimens consist of aluminium face sheets with epoxy adhesive films, $1 \mathrm{~mm}$ thick each and a honeycomb aramid core, $8 \mathrm{~mm}$ high. Static bending tests allows to determine the deflection variation as a function of the force applied which will be exploited to carry out fatigue tests on EPSIFLEX machine according to AFNOR NF 54-606 standard. 


\section{Material specifications}

The sandwich structures consist of:

- Two soles or skins, of low thickness. These skins are made of relatively high strength materials.

- A thicker core of low density.

The skin and sole are mechanically separable. The properties of these materials can therefore be modified by varying the proportions of their constituents or the constituent properties themselves. These adjustments make it possible to achieve the desired properties to respond to well-identified applications.

The core comes in different forms, either solid core of foam or wood and hollow core. Among the various composite families, the one that generally results from the combination of a core between two skins is well known (Fig. 1).

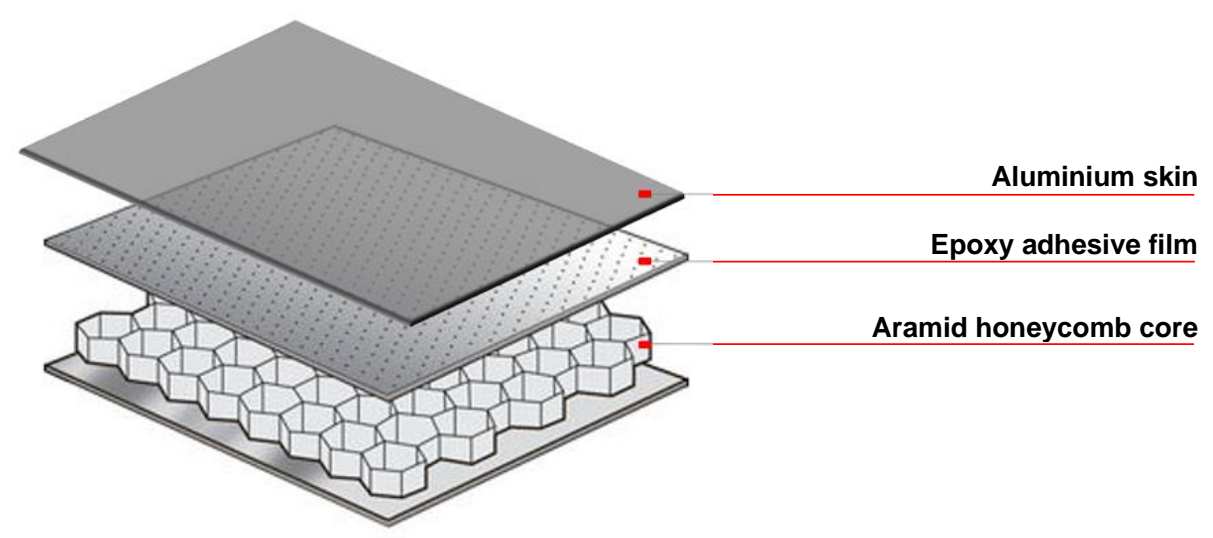

Fig. 1 Sandwich panel components

The use of sandwich material is also spreading in the building industry for their excellent thermal insulation characteristics. These materials can be made in different elements:

- For the skin: aluminium, steel, wood, plastic, strengthened resins of organic or inorganic fibres (composite materials)

- For the core: balsa, honeycombs made of polypropylene, aluminium, nomex or alveolar foam.

The specimens are cut according to the "L" direction of sandwich panel cells with a density of $148 \mathrm{~kg} / \mathrm{m}^{3}$, with aluminium skins and a honeycomb-shaped aramid core. Their dimensions (Fig. 2) have been defined according to the specifications of standard AFNOR NF 54-606. The width $b$ of the specimen is set at $25 \mathrm{~mm}$ to meet the standard requirements. The exact skin thickness, with adhesive film, $t f$ is $2 \mathrm{~mm}$, for the core $c=8 \mathrm{~mm}$ and for the structure $h=$ $12 \mathrm{~mm}$. The total length $\mathrm{L}$ of the test specimen is $200 \mathrm{~mm}$.

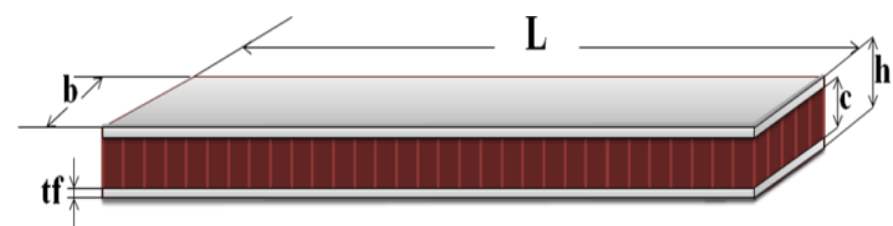

Fig. 2 Sandwich specimen dimensions according to AFNOR standard NF 54-606 


\section{Procedure}

Static bending tests were performed on a WDW-5 computer controlled universal testing machine (Fig. 3) with load cell of $50 \mathrm{kN}$. This machine was manufactured in China by Jinan (Shandong). The fatigue tests were carried out on a machine of the type EPSIFLEX (Fig. 4) with load cell of $250 \mathrm{daN}$ of imposed arrow. A force sensor, mounted on the cell, transmits the measurements to a connected computer-assisted navigation (CAN), equipped with processing results software. This machine was manufactured in France (Villeurbanne) by PRODEMAT (Instrumentation of Modern Technical Materials Control).

The experimental tests are carried out in two stages:

First, static 3-point bending tests are carried out, for four test pieces, on the machine described above (Fig. 3)._This made it possible to obtain the force-displacement curves (Fig. 5). On these curves, the value of the average elastic limit force taken as maximum loading force was determined $(\mathrm{Fmax}=\mathrm{Fel})$ because the stresses are limited to the elastic domain.

Thereafter, 3-point bending fatigue tests are performed on the Epsiflex fatigue device (Fig. 4)_for 3 loading levels of Fmax $(\mathrm{Fo}=90 \%, \mathrm{Fo}=80 \%$ and $\mathrm{Fo}=70 \%)$. As this fatigue machine is of constant deformation, it is necessary to determine the maximum deflection corresponding to Fo for each level.

In order to avoid test tubes moving, a pretension Fmin is applied for each level which generates an arrow fmin.

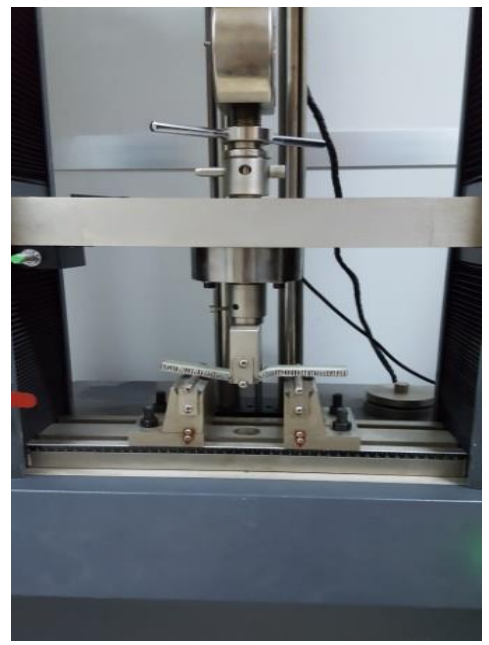

Fig. 3 Static bending test machine, WDW-5

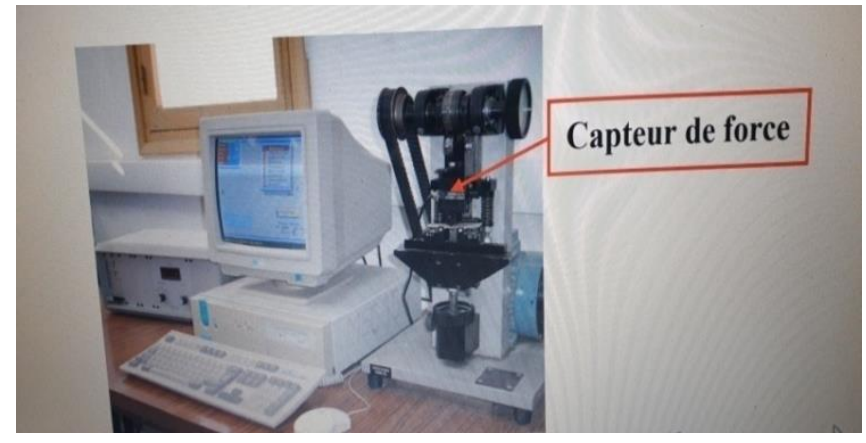

Fig. 4 Bending fatigue testing device, Epsiflex 


\section{$4 \quad$ Test results}

Static tests are carried out on the basis of four test tubes. Graphical results obtained show the loading force as a function of displacement (Fig. 5). The experimental results are carefully examined in the elastic zone.

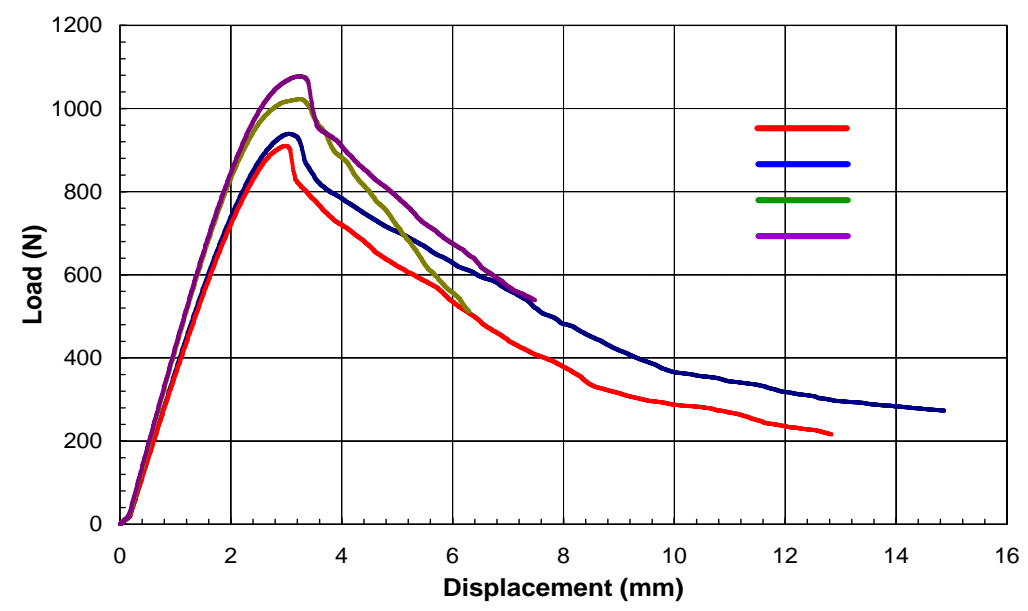

Fig. 5 Static bending tests

Respecting a load ratio of $\mathrm{R}=0.2$, the endurance tests (Fig. 6) are carried out for three loading level $(90 \%, 80 \%, 70 \%)$ according to the maximum loading of the elastic limit. The frequency is set constant to the value of $5 \mathrm{~Hz}$.

(a)

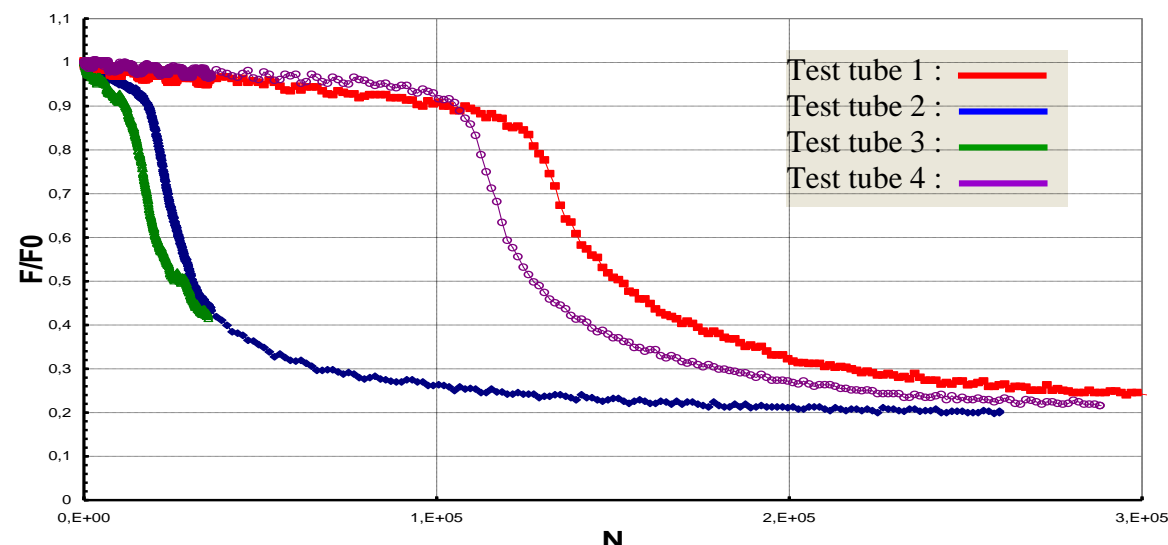

(b)

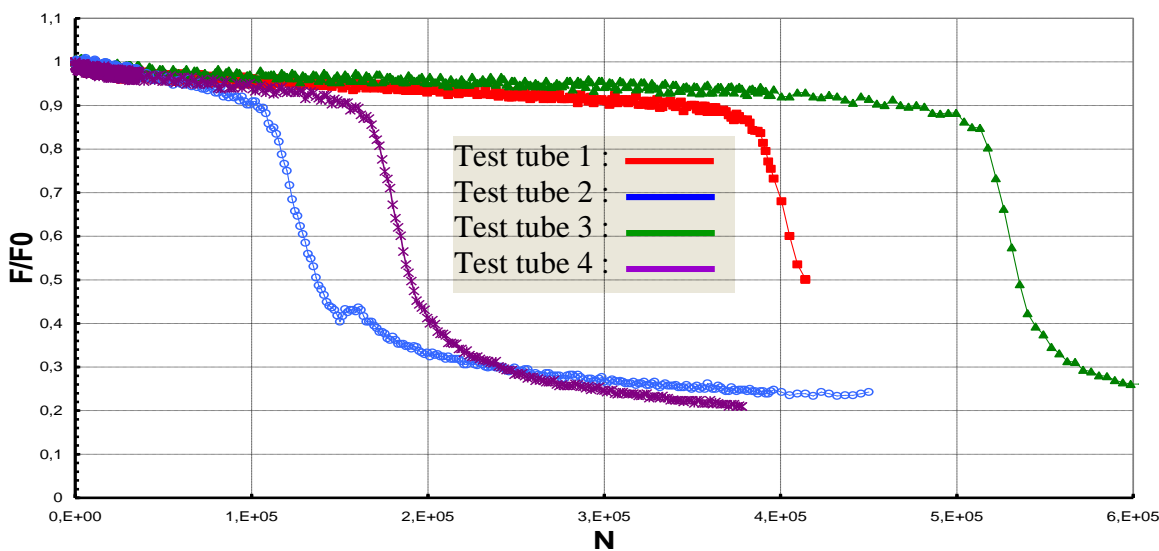


(c)

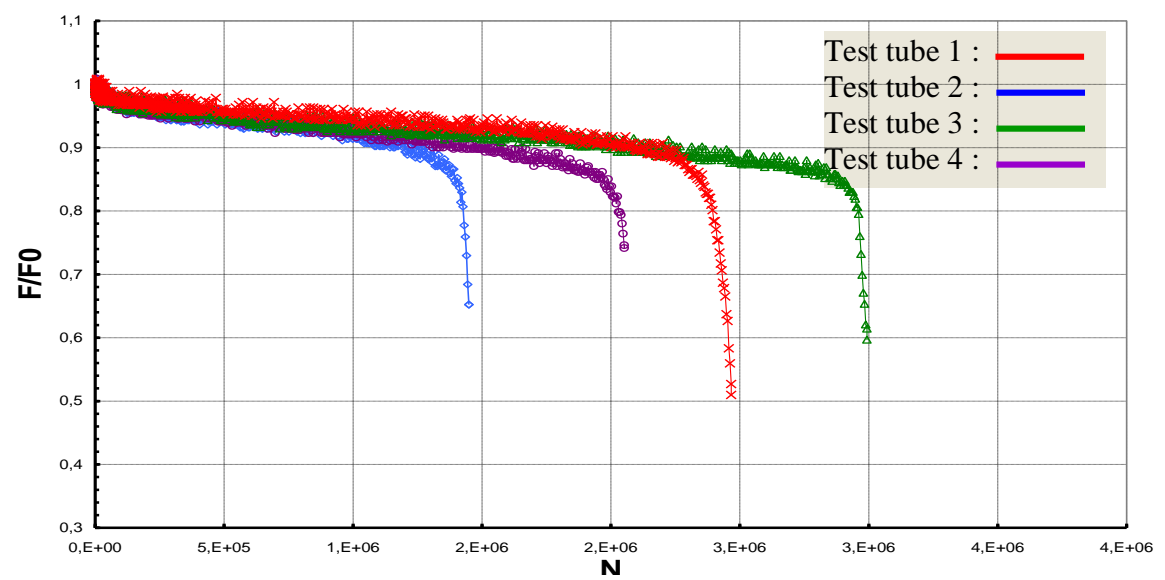

Fig. 6 Rigidity loss curves: (a) 90\% load, (b) 80\% load, (c) 70\% load

For the drawing of Wöhler curves, the experiments are carried out at constant deformation amplitude (CDA) with two end test criteria of $90 \%$ and $75 \%$ (Tab. 1 and Tab. 2). The loading ratio $\mathrm{R}$ and excitation frequency $f r$ are constant.

Tab. 1. Experimental data with test end criteria of $90 \%, \mathrm{R}=0.2$ and $f r=5 \mathrm{~Hz}$

\begin{tabular}{|c|c|c|c|c|c|}
\hline & & $1^{\text {st }}$ value & $2^{\text {nd }}$ value & $3^{\text {rd }}$ value & $4^{\text {th }}$ value \\
\hline \multirow{5}{*}{$\begin{array}{l}90 \% \\
\text { Load }\end{array}$} & $\mathrm{N}$ & 11750 & 18250 & 96050 & 105050 \\
\hline & F/FO & 0.9 & 0.9 & 0.9 & 0.9 \\
\hline & Max arrow amplitude (mm) & 1.8 & 1.8 & 1.8 & 1.8 \\
\hline & Deformation amplitude & 0.015 & 0.015 & 0.015 & 0.015 \\
\hline & Stress amplitude (MPa) & 1050 & 1050 & 1050 & 1050 \\
\hline \multirow{5}{*}{$\begin{array}{l}80 \% \\
\text { Load }\end{array}$} & $\mathrm{N}$ & 102050 & 154550 & 321050 & 468050 \\
\hline & $\mathrm{F} / \mathrm{FO}$ & 0.8 & 0.8 & 0.8 & 0.8 \\
\hline & Max arrow amplitude (mm) & 1.57 & 1.57 & 1.57 & 1.57 \\
\hline & Deformation amplitude & 0.013 & 0.013 & 0.013 & 0.013 \\
\hline & Stress amplitude (MPa) & 918 & 918 & 918 & 918 \\
\hline \multirow{5}{*}{$\begin{array}{l}70 \% \\
\text { Load }\end{array}$} & $\mathrm{N}$ & 1143050 & 1435550 & 2007050 & 2079050 \\
\hline & $\mathrm{F} / \mathrm{FO}$ & 0.7 & 0.7 & 0.7 & 0.7 \\
\hline & Max arrow amplitude $(\mathrm{mm})$ & 1.375 & 1.375 & 1.375 & 1.375 \\
\hline & Deformation amplitude & 0.013 & 0.013 & 0.013 & 0.013 \\
\hline & Stress amplitude (MPa) & 918 & 918 & 918 & 918 \\
\hline
\end{tabular}

Tab. 2. Experimental data with test end criteria of $75 \%, \mathrm{R}=0.2$ and $f r=5 \mathrm{~Hz}$

\begin{tabular}{|c|c|c|c|c|c|}
\hline & & $1^{\text {st }}$ value & $2^{\text {nd }}$ value & $3^{\text {rd }}$ value & $4^{\text {th }}$ value \\
\hline \multirow{5}{*}{$\begin{array}{l}90 \% \\
\text { Load }\end{array}$} & $\mathrm{N}$ & 16650 & 22550 & 114050 & 132050 \\
\hline & F/FO & 0.9 & 0.9 & 0.9 & 0.9 \\
\hline & Max arrow amplitude (mm) & 1.8 & 1.8 & 1.8 & 1.8 \\
\hline & Deformation amplitude & 0.015 & 0.015 & 0.015 & 0.015 \\
\hline & Stress amplitude & 1050 & 1050 & 1050 & 1050 \\
\hline \multirow{5}{*}{$\begin{array}{l}80 \% \\
\text { Load }\end{array}$} & $\mathrm{N}$ & 120050 & 175550 & 394550 & 522050 \\
\hline & $\mathrm{F} / \mathrm{FO}$ & 0.8 & 0.8 & 0.8 & 0.8 \\
\hline & Max arrow amplitude $(\mathrm{mm})$ & 1.57 & 1.57 & 1.57 & 1.57 \\
\hline & Deformation amplitude & 0.013 & 0.013 & 0.013 & 0.013 \\
\hline & Stress amplitude & 918 & 918 & 918 & 918 \\
\hline \multirow{5}{*}{$\begin{array}{c}70 \% \\
\text { Load }\end{array}$} & $\mathrm{N}$ & 1435550 & 2047550 & 2416550 & 2965550 \\
\hline & F/F0 & 0.7 & 0.7 & 0.7 & 0.7 \\
\hline & Max arrow amplitude (mm) & 1.375 & 1.375 & 1.375 & 1.375 \\
\hline & Deformation amplitude & 0.013 & 0.013 & 0.013 & 0.013 \\
\hline & Stress amplitude & 918 & 918 & 918 & 918 \\
\hline
\end{tabular}




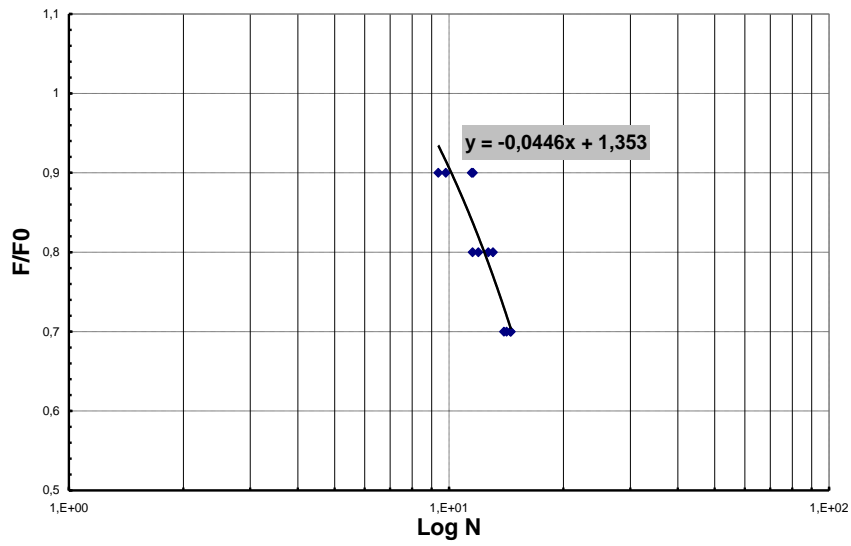

(a)

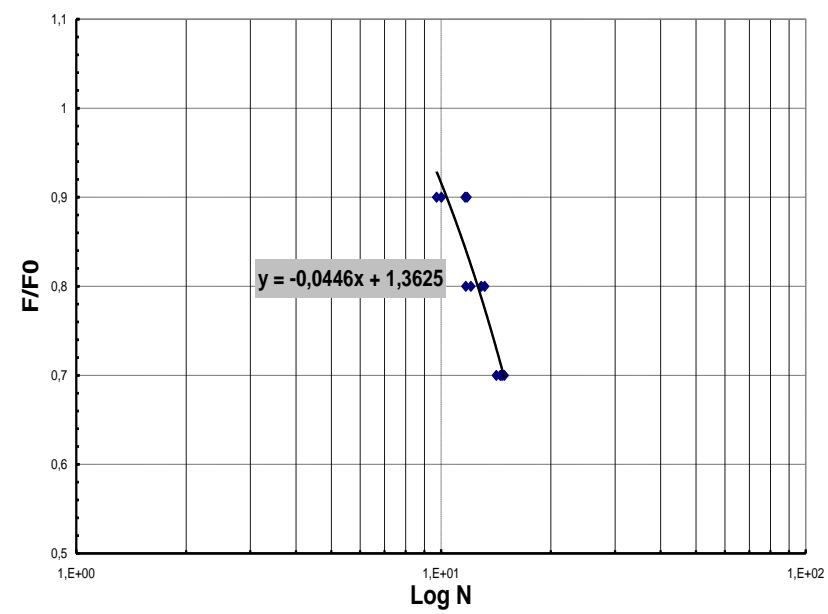

(a)

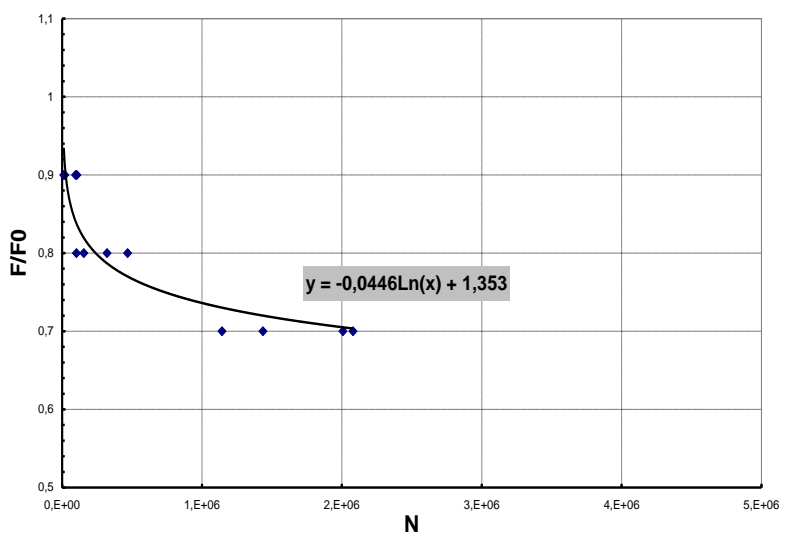

(b)

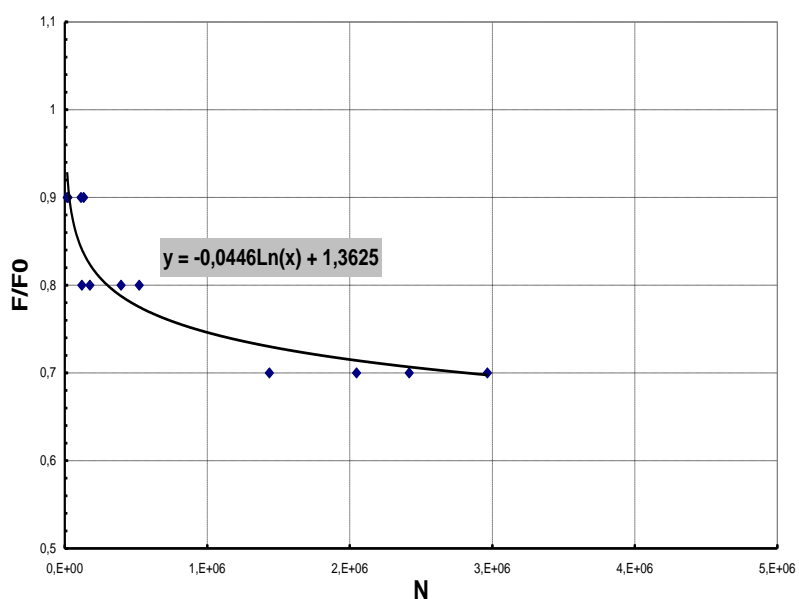

(b)

Fig. 7 (a) Fatigue curves (b) Wöhler curves

Considering the fracture mechanics analyses, in fatigue and bending testing (Figs 8 and 9), optical microscope together with image analysis is utilized. The equipment consists of three parts: optical microscope, macro observation system and the PC with software of image analysis.

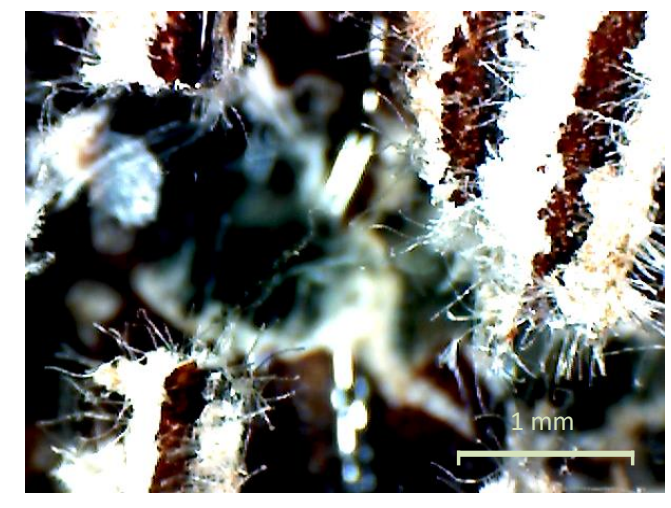

(a)

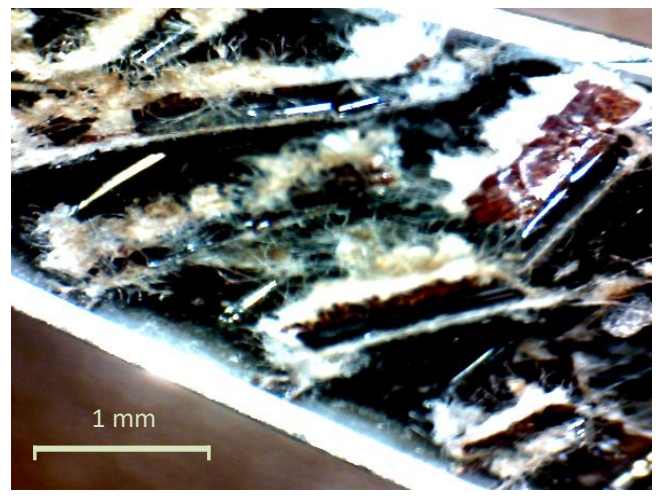

(b)

Fig. 8 Shearing of the core walls (a) in static bending, (b) in fatigue bending 


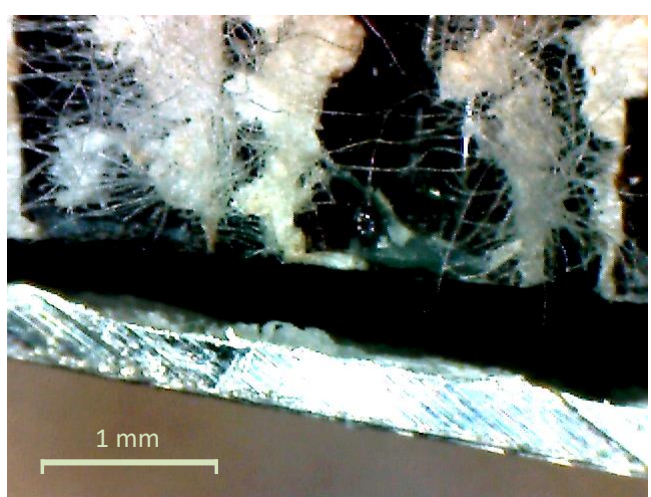

(a)

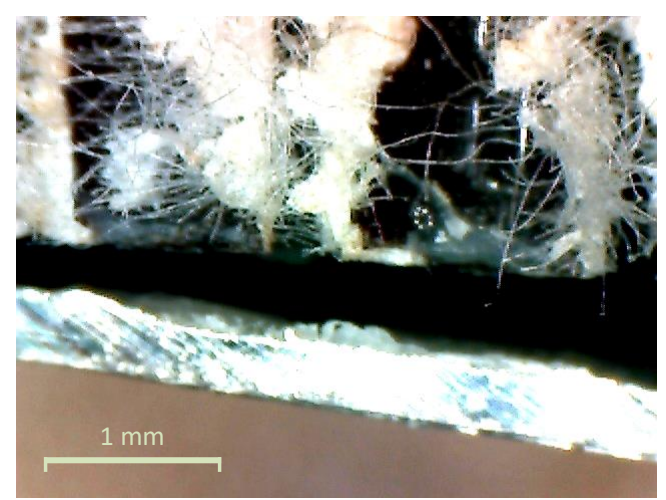

(b)

Fig. 9 Disbond of the core (a) in static bending, (b) in fatigue bending

\section{Discussion}

The undertaken experimental investigation of the fatigue behaviour of sandwich-structured aramid/aluminium specimens under three-point bending loads indicates the outcomes discussed below.

For static tests, one could distinguish three zones of deformation (Fig. 5):

- A linear zone corresponding to an elastic deformation up to a limit value ( $\mathrm{Fe} \approx 720 \mathrm{~N}$ ).

- A non-linear zone corresponding to a plastic deformation up to the maximum value (Fm $\approx$ $960 \mathrm{~N})$.

- A nonlinear zone corresponding to a plastic deformation of a decreasing rate without reaching a sudden rupture.

With regard to the damage, one notes:

- Strong indentation of the skins.

- Cells buckling causing the shearing of the core cells.

- Core separation (Fig. 9a).

It is necessary to maintain the stresses to which the material will be subjected in the elastic range. The maximum force taken Fo is the limit elastic force.

Through fatigue tests examination, the rigidity loss presents distortions due to the different positions of the specimen's cutting plane relative to the extreme cells contours which modify the sole section and, consequently, its quadratic moment on the one hand and the irregularity of the adhesive film between skins and core on the other hand (Fig. 6).

According to the Wöhler curves (Fig. 7b), the endurance limit of this material is reached for the following cycle numbers:

- $2.10^{6}$ for a $90 \%$ test end criterion.

- $3.10^{6}$ for a $75 \%$ test end criterion.

The damage is manifested by:

- A slight indentation of the skins due to the plastic deformation (Fig. 9b).

- A buckling cells causing their shears (Fig. 8).

- The core detachment (Fig. 9).

\section{CONCLUSION}

The purpose of the 3-point bending fatigue tests in this study is to determine the changes in mechanical properties for stresses below the end of proportionality. The results obtained 
allowed the determination of the stiffness loss curves and the Wöhler curves in order to optimize the loading conditions and the lifetime of the sandwich composite material. Hence the maximum stresses studied are in the interval corresponding to the start of damage determined previously and the end of linearity. The signal is sinusoidal, with a frequency of 5 $\mathrm{Hz}$ up to 3 million cycles with a load ratio of 0.2 . The first non-instrumented tests allow us to assess the loss of rigidity as a function of the maximum stress imposed. The loss of rigidity becomes significant for a large number of cycles. Indeed, for moderate cyclic loadings at average frequencies (from 1 to $10 \mathrm{~Hz}$ ), the loss of rigidity presents a late manifestation. Therefore, they can replace the usual materials by benefiting from their lightness and low cost.

The fatigue test graphs represent the stress ratio F/Fo as a function of lifetime (expressed in $\log \mathrm{N}$ ). The objective was not to reconstruct the Wöhler curve in its entirety but to choose a loading level in order to identify the lifetime, namely the failure cycles number of our tests. It is important to closely observe the failure sections in order to build a database of the different failure modes. In order to determine the different mechanisms responsible for the rupture, a low zoom fracture facies show a first mode of rupture, the core shearing. The ruptured surface has a scalloped appearance with open cells, some walls are clearly sheared and others rather torn off. One notes that the ruin of the sole occurs prematurely in accordance to the skins ruin, which omits the abrupt and fatal nature of the damage.

\section{REFERENCES}

[1] Berthelot, J. M. "Composite Materials: Mechanical Behaviour and Structural Analysis", Springer, Canada, 1998. ISBN-13 : 978-0387984261

[2] Benveniste, Y. "The effective mechanical behaviour of composite materials with imperfect contact between the constituents", Mechanics of Materials, 4 (2), pp. 197 208, 1985. DOI: 10.1016/0167-6636(85)90016-X

[3] Magalhães, A. G., Marques, A. T., Oliveira, F. M. F., Soukatchoff, P., de Castro, P. T. "Mechanical behaviour of cementitious matrix composites", Cement and Concrete Composites 18 (1), pp. 9 - 22, 1996. DOI: 10.1016/0958-9465(95)00035-6

[4] Burman, M., Zenkert, D. "Fatigue of undamaged and damaged honeycomb sandwich beams", Journal of Sandwich Structures and Materials 2 (1), pp. 50 - 74, 2000. DOI: $10.1177 / 109963620000200103$

[5] Chemami, A., Bey, K., Gilbert, J., Azari, Z. "Behaviour of composite sandwich foamlaminated glass/epoxy under solicitation static and fatigue", Composites Part B: Engineering 43(3) , pp. 1178 - 1184, 2012. DOI: 10.1016/j.compositesb.2011.11.051

[6] Aglan, H., Wang, Q. Y., Kehoe, M. "Fatigue behaviour of bonded composite repairs", Journal of Adhesion Science and Technology 15 (13), pp. 1621 - 1634, 2001. DOI: $10.1163 / 156856101753207715$

[7] Bisagni, C., Furfari, D., Pacchione, M. "Experimental investigation of reinforced bonded joints for composite laminates", Journal of Composite Materials 52 (4), pp. 431 - 447, 2018. DOI: 10.1177/0021998317708021

[8] Cheng, H. C., Hwu, F. S. "Fatigue reliability analysis of composites based on residual strength", Advanced Composite Materials 15 (4), pp. 385 - 402, 2006. DOI: $10.1163 / 156855106778835212$

[9] Hufenbach, W., Jaschinski, J., Weber, T., Weck, D. "Numerical and experimental investigations on HYLITE sandwich sheets as an alternative sheet metal", Archives of 
Civil and Mechanical Engineering 8 (2), pp. 67 - 80, 2008. DOI: 10.1016/S16449665(12)60194-0

[10] Boisseau, A., Davies, P., Thiebaud, F. "Fatigue behaviour of glass fibre reinforced composites for ocean energy conversion systems", Applied Composite Materials 20, pp. 145 - 155, 2013. DOI: $10.1007 / \mathrm{s} 10443-012-9260-0$

[11] Sameer Kumar, D., Suman, K. N. S., Palash, P., Tara Sasanka, C. "Performance evaluation of surface modified nano $\mathrm{Al}_{2} \mathrm{O}_{3}$ (p) reinforced AZ91E composites under impact and fatigue loading conditions", Strojnícky časopis - Journal of Mechanical Engineering 70 (1), pp. 29 - 38, 2020. DOI: 10.2478/scjme-2020-0003

[12] Dovhopolov, A., Nekrasov, S., Zhyhylii, D., Savchenko, Y., Stupin B. "Modeling of a stress-strain state of detachable connection in details of reinforced composite materials with cea method", Strojnícky časopis - Journal of Mechanical Engineering 70 (1), pp. 17 - 28, 2020. DOI: $10.2478 /$ scjme-2020-0002

[13] Ashenai Ghasemi, F., Ghorbani, A., Ghasemi, I. "Mechanical, thermal and dynamic mechanical properties of $\mathrm{PP} / \mathrm{GF} / \mathrm{xGnP}$ nanocomposites", Mechanics of Composite Materials 53, pp. 131 - 138, 2017. DOI: 10.1007/s11029-017-9647-y

[14] Xu, C., Song, L., Zhu, H., Meng, S., Xie, W., Jin, H. "Experimental investigation on the mechanical behaviour of 3D carbon/carbon composites under biaxial compression", Composite Structures 188, pp. 7 - 14, 2018. DOI: 10.1016/j.compstruct.2017.11.035

[15] Abbasloo, A., Maheri, M. R. "On the mechanisms of modal damping in FRP/honeycomb sandwich panels", Science and Engineering of Composite Materials 25 (4), pp. 649 - 660, 2018. DOI: $10.1515 / \mathrm{secm}-2015-0444$

[16] Mohamad Hamdan, M. H., Siregar, J. P., Thomas, S., Jacob, M. J., Jaafar, J., Tezara C. "Mechanical performance of hybrid woven jute-roselle-reinforced polyester composites", Polymers and Polymer Composites 27 (7), pp. 407 - 418, 2019. DOI: $10.1177 / 0967391119847552$

[17] Moheimani, R., Sarayloo, R., Dalir, H. "Failure study of fibre/epoxy composite laminate interface using cohesive multiscale model", Advanced Composites Letters 29, pp. 1 19, 2020. DOI: $10.1177 / 2633366$ X20910157 